\title{
Driver information systems - A North American perspective
}

\author{
KAN CHEN \\ University of Michigan, Ann Arbor, MI 48109 USA
}

\section{Accepted 20 June 1990}

Key words: Intelligent Vehicle-Highway Systems, route guidance, automobile navigation, automatic vehicle identification

\begin{abstract}
Driver information systems (DIS) are considered in North America as a major category of Intelligent Vehicle-Highway Systems (IVHS), which offers to improve the efficiency and safety of driving by means of an amalgamation of information technology with vehicle and highway technologies. Traditionally North America has basic strengths in a number of information technologies that are relevant to DIS. Due to a hiatus in federal funding in the early 1980 s. DIS development in North America during the past decade has emphasized autonomous systems on the vehicles until recently. The current acceleration of IVHS development in the United States has resulted from a number of converging forces and has provided the impetus for developing advanced driver information systems (ADIS) that integrates the vehicle and the highway. Large-scale demonstration and implementation of ADIS will hinge on the major legislations in the near future, and on the successful development of public-private sector partnerships in IVHS.
\end{abstract}

\section{Past history}

With the dominant role of motor vehicles in the total transportation system in North America, the maintenance and improvement of the efficiency and safety of highway travel have been of continuous concern to American societies. Advanced vehicle-highway systems, ranging from electronic route guidance systems (Stephens et al. 1968) to automated highways, have been an area of research and development on the continent for decades. It is noteworthy that initial studies of the automated highway were conducted in the late 1950s (Gardels 1960), even though two of the frequently cited references on the subject are based on more recent studies, which had continued for a number of years at Ohio State University (Fenton et al. 1980) and at General Motors (GM 1981), both supported by the U.S. Department of Transportation. All of these studies involved both lateral and longitudinal vehicle guidance and control, including appropriate installations on the highway. 
With the substantial reduction of the Federal Goverment's role in civilian technology development during the 1980s, the U.S. research activities in advanced vehicle-highway systems dwindled until recently. Since the highway is owned and operated by the public sector, without federal funding the major developmetns have been mainly restricted to smart cars that operate independently of the highway. In contrast, the efforts to develop and demonstrate the advanced use of communications and control technologies on both the vehicle and the highway in Europe and Japan have accelerated, perhaps as a result of the more pressing needs these due to higher densities of population and motor vehicles. especially in the urban areas.

The announcements of the billion-dollar DRIVE and PROMETHEUS programs in Europe (Panik 1988) and the comparable AMTICS and RACS programs in Japan (Koshi 1988) during the past few years have jolted the U.S. to revive its activities in advanced vehicle-highway technology. However, with the passage of time, the revived activities are now taking on characteristics which differ, both technically and institutionally, from that seen through the 1960s and 1970s. Importantly, more emphassis is now put on the nearer-term use of driver information systems (DIS) for driver-advisory functions - more along the direction of the Electronic Route Guidance System (ERGS) whose development was interrupted in the early 1970 s (Rosen et al. 1970) - rather than on the longer-term use of control technologies for automation purposes. There is also a wider range of organizations working in concert from both the private and public sectors than in the past to link the vehicles and highways through information technology - hence the emerging program title, Intelligent Vehicle-Highway Systems or IVHS. Recent U.S. studies (US DOT 1989: US Congress 1989) have grouped IVHS technologies into three generic functional areas, listed below along with examples:

- Advanced Traffic Management Systems (ATMS) - automatic toll billing, automatic incident detection, adaptive traffic signal controls, etc.

- Advanced Driver Information Systems (ADIS) - automatic vehicle location, automatic vehicle navigation, motorist information, cooperative route guidance, collision warning and in-vehicle signage, etc.

- Automated Vehicle Control Systems (AVCS) - collision avoidance, speed and headway keeping, automated highway, automated guideway, etc.

In general, most ATMS technologies are in the deployable stage; ADIS technologies will need near-term research and development; while AVCS technologies will require longer-term research before they can be applied 
reliably. It is the intent of this paper to focus on the development of DIS in North America, ranging from the past and current achievements to the projection of the more advanced technologies in ADIS.

\section{Modular technologies}

Traditionally North America has enjoyed substantial strengths in the realm of advanced information technologies, many of which are relevant to DIS. Both the defense and the civilian sectors have contributed to the development of these technologies. For example, the global positioning system (GPS) for navigation has come out of the defense sector and its operation will be maintained by the U.S. Government. On the other hand. the cellular telephone has been developed mainly for civilian communications, and at present the U.S. has the largest number of cellular subscribers in any country bloc - nearly 3.5 million in 1989 and growing rapidly toward 5.3 million by the end of 1990 (Meehan 1990).

The three basic navigation systems for IVHS are dead reckoning, LORAN, and GPS. Each can be augmented by map matching and all can be used to complement one another. The map matching algorithm is based on a form of artificial intelligence which helps to correct navigation errors (Honey \& Zavoli 1986). It is an example of ingenious software development, another traditional strength of American technology. At present, Loran $C$ is most widely used for commercial and government vehicle location and fleet dispatch; whereas GPS is least applied since not all the satellites are in orbit for 24-hour coverage and the per unit receiver cost (around $\$ 2,000$ to $\$ 3,000)$ is still too expensive for most users.

Existing communications systems that can be or have been used for IVHS in North America include microwave, mobile data terminal (MDT). regular broadcasts and their subcarriers, as well as cellular radio. Towerbased microwave communications can be either conventional or trunked. MDT has been used for a number of years for data transmitted between vehicles and base stations. Highway information has been broadcast to drivers by both commercial and dedicated radio stations. Cellular radio has the potential to become a dominant medium for two-way IVHS communications because of its selectivity in information delivery. However, the current cellular infrastructure is mainly analog and circuit switched, and thus not yet suited for digital communications which is much more efficient than analog for data communications.

As in any information and control systems, inputs and outputs are frequently the Archilles heels of these systems. For DIS, it would be very 
important to get accurate and timely information of interest to the driver. At present, even static information such as maps and "yellow page" information are not yet widely available in digital form for DIS. Dynamic or real-time traffic and "yellow page" information are even less available. The most common sensors used to get traffic conditions in North America are the induction loop detectors buried under the road pavement, and their reliability, especially in hostile-climate zones, has been a serious problem. Various algorithms are being developed to deduce traffic parameters and to detect incidents from these loop signals (Persaud et al. 1990). Innovative systems to analyze traffic pattern from video monitors have been developed but not yet widely accepted (Michalopoulos et al. 1990).

Interfaces between DIS and the driver includes visual and auditory displays to the driver, and voice-actuated as well as tactile input equipment for the driver to control and/or query the DIS. A host of devices and subsystems have been developed and demonstrated, including head-up displays, electrocic maps, synthetic voice displays, and voice-dialed cellular phones. This is an area where reliability. cost reduction. and human factor considerations will determine their future acceptance and deployment.

As indicated previously, collision warning is another functional area of ADIS. In spite of well over twenty years of study in this area, the problem of false alarms is still not solved with sufficient practical acceptance. An expert in this area (Grimes 1989) compares the relative merits of radar, lidar. and sonar for collision warning in the following way.

At highway speeds and sensing ranges of 80 to 100 meters, the relatively low speed of sound and possible beam displacement by cross winds make sonar data too stale and too unreliable. Lidar can be reliably used to detect dark or dirty, uncooperative targets to a maximum range of only 40 to 50 meters, and a mininum range of 80 meters is needed for adaptive cruise control and safety warning. Neither can lidar be modulated to obtain accurate and independent readings of range and closing speed. This leaves radar. Although the difference between roadway clutter and desired targets cannot be determined well enough in the radar front end, considerable progress has been made using processing algorithms ... The remaining high-cost radar problem is the antenna. An antenna is needed that can be designed into the front of small vehicles, is low in cost, and is capable of providing target angle, range, and closing speed.

In sum, although North America is in a good position to adapt its 
information technologies developed outside the automotive industry to DIS, there is a great need for adapting these modular technologies to the specific needs of DIS.

\section{Recent developments}

The recently established IVHS programs in Europe and Japan mentioned previously is only one of several causes of the revived U.S. interests in IVHS. The other converging forces pushing for the recent acceleration of IVHS development are the stress of increased traffic on urban road systems and a pervasive technology push which promises to match up well with the technical needs of IVHS (Chen \& Ervin 1989). In North America, there are already a few automatic toll billing and automatic vehicle locator systems in operation or under installation, and the most active IVHS project to date has been the Heavy Vehicle Electronic License Plate (HELP) Program started in 1986, which combines automatic vehicle identification, weigh-in-motion and automatic vehicle classification technologies with a networked data communications and processing system for improving trucking productivity (Davies et al. 1989).

In contrast to the situations in Europe and Japan, there is currently no formal IVHS program in the United States or Canada that is national in scope. The most visible activity to date is in state of California. A fouryear old Program in Advanced Technology for Highways (PATH) at the University of California at Berkeley was derived from a longer-term project on highway electrification as a vehicular power source and now has an emphasis on AVCS (Kanafani \& Parsons 1989).

Efforts begun by the Berkeley group in 1986 to stimulate research activities elsewhere in the U.S. provided the catalyst for at least two other university-based programs, one at Texas A\&M University and the other at the University of Michigan. As each university tries to build upon its traditional interests and strengths, Texas $A \& M$ has extrapolated from highway and traffic engineering, including the perspective of defense industry capabilities in Texas. Thus, one of the two current projects at Texas A\&M (Bridges 1989) is real-time signal control, and the other is on autonomous vehicles, which has been a subject of investigation under the U.S. Department of Defense.

With its proximity to and close relationship with the automotive industry, the University of Michigan formulated its IVHS program in 1988 with two defining characteristics:

- extrapolation from the interests and capabilities of the automotive industry, and 
- an incrmental approach to IVHS technology R\&D and deployment (Chen \& Ervin 1989).

These characteristics have apparently captured the interests of a wide spectrum of highway users and governmental as well as industrial sponsors for the Michigan program. Given these backgrounds and histories, the three state universities have naturally concentrated their efforts with the following complementarity: Texas A\&M on ATMS, Michigan on ADIS, and California on AVCS.

Other universities, including Massachusetts Institute of Technology, University of Minnesota, among others, are in the process of developing and refining their own programs in IVHS. The emergence of universitybased IVHS programs in the U.S. bespeaks the relatively unique roles of the university in this country in facilitating interactions between the private and public sectors as well as in conducting research. In other words, American universities have sought, and have been accepted, to play the roles of facilitating both institutional and technical innovations in IVHS.

Separately, a demonstration program known as Pathfinder has been set up in Los Angeles. involving the California Department of Transportation, the Federal Highway Administration, and General Motors to assess the effectiveness of a particular interactive route guidance system (Sumner \& Mammano 1989). Although quite small in scope by comparison to similar projects underway in Europe and Japan, the Pathfinder project does signify a serious interest of both the private and public sectors in the U.S. to cooperate in the IVHS area.

Even though there has been no national program in America, the various parties involved in the diverse activities in IVHS in North America (including Canada) have communicated and worked together under the Mobility 2000 consortium, which brings together the stakeholders in an ad hoc effort to advance the American interest in IVHS and to clarify the technical and institutional issues. The consortium was initially convened at the Federal Highway Administration in late 1987, and has held a number of meetings and workshops, involving individuals from federal and state agencies, automotive and communication industries, universities and national academies, consultants and research institutes. The work conducted by this group (Mobility 2000 1989) has been used as a major input to the U.S. Congressionally-mandated report on IVHS to be issued by the U.S. Department of Transportation (US DOT 1989), and to the U.S. Congressional Office of Technology Assessment staff report on IVHS (US Congress 1989).

Expectations have been that a special opportunity for U.S. action will materialize in 1991 when Congress, marking the conclusion of the Inter- 
state Highway Program, enacts a watershed Highway Bill that will lead to the adoption of the next generation of highway technologies that will impart intelligence to the new and existing road systems. A national momentum is gathering to underscore the importance of IVHS, along with continual federal allocation for highway construction and maintenance, in the Congressional hearings that are being held on the 1991 Highway bill. On the private-sector side, the Highway Users Federation (HUF) has set up an ad hoc committee to press Congress to allocate \$1 billion for IVHS research, development and demonstration (RD\&D). On the public-sertor side, the leadership has been taken by the American Association of State Highway \& Transportation Officials (AASHTO), whose policy committee has endorsed a similar resolution recently.

\section{Future projections}

The momentum of IVHS development in North America is such that one can make reasonable projections of its market penetration in the foreseeable future. This is particularly true for advanced driver information systems (ADIS) which, as mentioned previously, is likely to undergo nearterm research and development probably earlier than automated vehicle control systems (AVCS). A recent Delphi survey (Underwood et al. 1989) based on inputs from over 30 experts from the sponsoring organizations of the Michigan-based IVHS program has produced the results shown in Fig. 1. Several interesting observations may be made about these projections. First, all the ADIS technologies are expected to make progress through the successive stages of laboratory tests, system introduction into the market place, majority use by commercial vehicles, majority use by all automobiles, and mandatory use by all road vehicles. However, most of the ADIS technologies are not expected to become mandatory. In fact, those ADIS technologies which are more advisory-oriented and more navigation-oriented are expected to be adopted earlier but may never become mandatory. Those which are more control-oriented are expected to be adopted later after the issues of reliablilty and legal liability are resolved. To the extent that some of the control-oriented technologies may prove to enhance safety, they may become mandatory eventully. The time scale is also interesting in that all the ADIS technologies are projected to find their way into most commercial vehicles within 5 to 20 years in the following order:

- Motorist information (MI)

- Automatic vehicle navigation (AVN) 
- Automatic vehicle location and identification(AVL)

- Cooperative route guidance (CRG)

- Collision warning $(\mathrm{CW})$

The above projections are based on the critical assumption that the U.S. Congress will allocate substantial resources to support research, developnemt, and demonstration of IVHS - in the order of \$1 billion recommended by AASHTO and HUF beginning 1992, as discussed previously.

If the above projections and assumption are true, then the future DIS in North America would go through the following three stages of functional development, as suggested by the scenario developed by the ADIS work group within Mobility 2000 (Mobility 2000 1990):

- The information stage

- The advisory stage

- The coordination stage

As most of the modular technologies for DIS are not fundamentally new, the basic research on ADIS is expected to be in the direction of system integration while the development activities would be in the directions of cost reduction, improved performance, and user acceptance. For example, the current basic research program at the University of Michigan emphasizes the integration of traffic analysis, system architecture, human factors, and safe vehicle control - all centered on the scenario of advising drivers if and how they should divert from their normal routes after the detection and verification of a non-recurrent incident (Galler \& Chen 1990). Basic research is also being conducted to assess the optimum distribution of intelligence between the vehicle and the highway, and the system architecture for interconnecting hundreds of thousands of smart moving terminals, one on each vehicle, that constantly enter and leave the real-time information-processing and communication network. Once established, such a network hopefully can be expanded with flexibility, not only to accommodate additional services but also to utilize unknown future technologies. Research will not be restricted only to system integration. As stated previously, input and output devices have been the weak links in IVHS. Fundamentally new sensors, such as those based on widearea sensing, may become important research areas.

On the development side, once the institutional framework for publicprivate sector partnerships and the infrastructure for vehicle-highway communications are established, vigorous product development is expected for ADIS by a number of competing firms in both the automotive and the electronics industries. Automotive electronics, which has gone through the three generations of devices, subsystem, and system integra- 


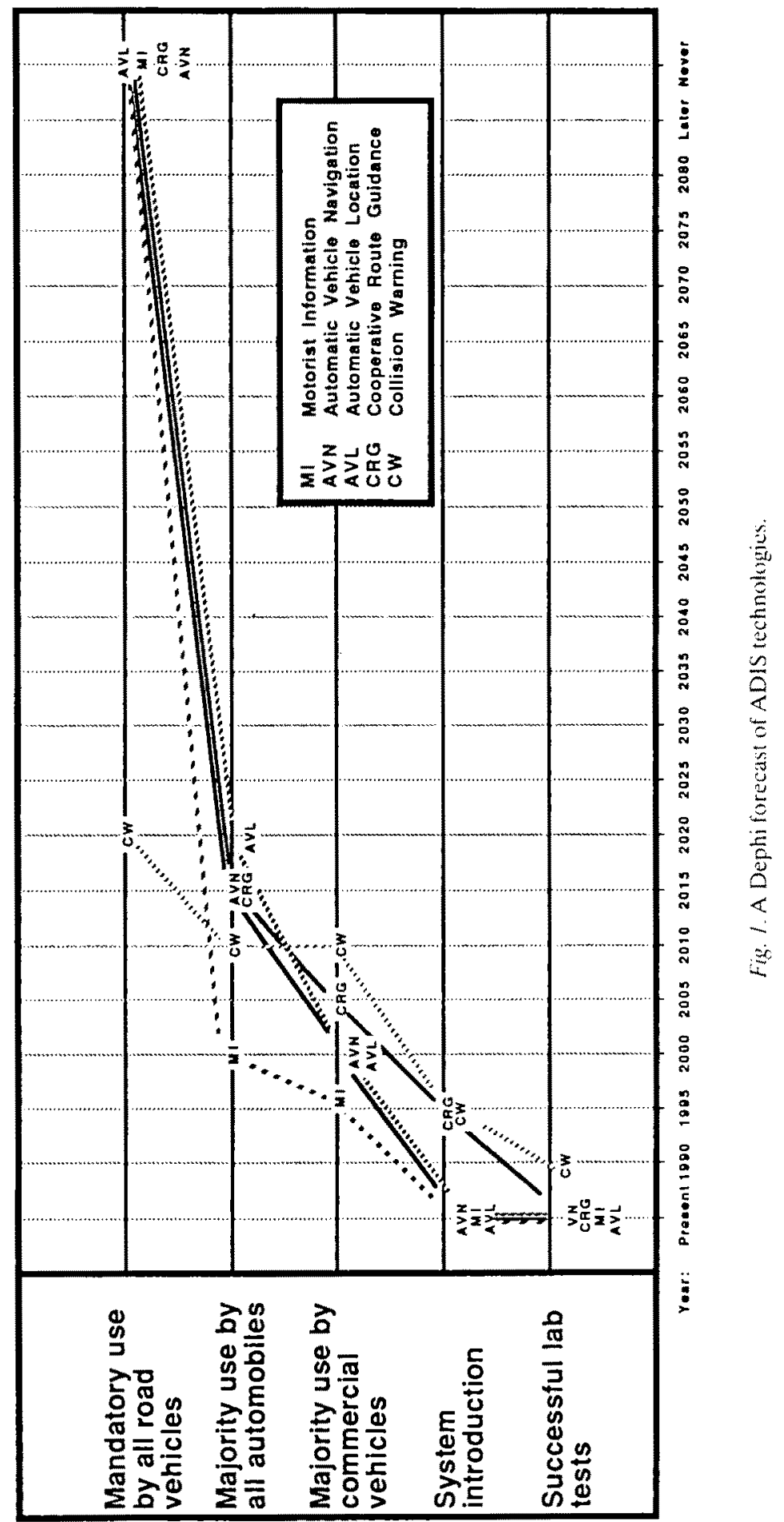


tion on the vehicle side (Rivard 1987), will enter the next generation in which system integration will include the highway as well as the vehicle. Future U.S. automobile navigation systems will probably integrate multiple navigation inputs (French 1987). Communications infrastructure development will also become significant. For example, new communication media - including digital cellular, roadside beacons, and satellite-based communication - are likely to be developed for ADIS functions.

As Europe and Japan have been ahead of North America in IVHS demonstrations, one can expect a host of catching-up activities in all sorts of demonstration projects in North America. Early demonstrations are likely to utilize existing and relatively inexpensive technologies - including telephones as well as radios for pre-trip planning information as well as on-route re-planning information. Later demonstrations will probably emphasize the more sophisticated ADIS functions such as cooperative route guidance and collision warning. In the near future, demonstrations similar to, but larger and more sophisticated than, the Pahtfinder project may be expected in various cities in Noth America. The Michigan Department of Transportation has already announced the dedication of a part of its Greater Detroit road network to a national IVHS laboratory, known as the Metropolitan Transportation Center, in the Greater Detroit area. This test bed will feature sophisticated infrastructure elements and is intended to facilitate the experimentation and demonstration of promising IVHS devices, vehicles, and subsystems beyond laboratory prototypes but not yet ready for full-scale deployment. These products and systems may be brought by any organization or consortia in the nation (and elsewhere in the world) to be tested in real traffic environment (Orne 1990). The proven and cost-effective IVHS technology could then be deployed to enhance highway travel efficiency and safety in Detroit, and elsewhere in Michigan and in the world.

This last point brings up the question of international competition versus cooperation. Everyone understands the reality of competition and its implication in world trade. At the same time, there are the needs for international standards as well as cooperation to speed up technical development and to reduce total development costs. However, globalization of IVHS remains to be a very complex process. Only time will tell how rapid and how smooth the multinational public-private sector partnership will develop for IVHS at the pre-competitive stage before the product developers and service providers enter into competition in all markets regardless of national boundaries. Conceivably the multiple formal international organizations (e.g., the Organization of Economic Cooperation and Development, the International Standards Organization, etc.) and informal groups and forums (e.g., Mobility 2000 in North 
America, PROMETHEUS in Europe, and JSK Foundation in Japan, etc.) can all work in concert to facilitate the mutually satisfactory resolution of the important issues of of international cooperation and competition in IVHS.

\section{References}

Bridges GS (1989) Advanced highway/vehicle programs: a Texas view. Record of the lst Vehicle Navigation \& Information Systems Conference, September, 1989

Chen K \& Ervin RD (1989) Developing a program in intelligent vehicle-highway systems in North America. Proceedings of the 20th International Symposium on Automotive Technology \& Automation (pp 1103-1113). May 29-June 2

Davies P Ayland N Hill C \& Sommerville F (1989) The heavy electronic license plate (HELP) programme. Proceedings of the 20th International Symposium on Automotive Technology and Automation (pp 1163-1173). May 29-June 2

Fenton RE et al. (1980) Intellectual studies in automatic vehicle control. Final report on FHWA/DOT contract DOT-FH-925. The Ohio State University, August

French RL (1987) U.S. automobile navigation: past, present, and future. Proceedings of the 16 th International Symposium on Automobile Technology and Automation. Florence Italy, May $11-15$

Galler BA \& Chen K (1990) System consideration for diversion advice and recommendation technology (DART). Proceedings of the 22nd International Symposium on Automotive Technology and Automation. Florence Italy, May 14-18

Gardels K (1960) Automatic Car Controls for Electric Highways. General Motors Research Laboratories: GMR-276. Warren Michigan, June

General Motors Transportation Systems Center (1981) Systems Studies of Automated Highway Systems. Report No. EP-81041 A, August

Grimes DM (1989) Guest editorial. IEEE Transactions on Vehicular Technology 38(3): $110-111$

Honey SK \& Zavoli WB (1986) Map matching augmented dead reckoning. 36th IEEE Vehicular Technology Conference Proceedings ( $p$ p 359-362). May 20-22

Kanafani A \& Parsons RE (1989) Program on advanced technology for the highway: Vehicle/highway research and development. Record of the 1st Vehicle Navigation and Information Systems Conference, September

Koshi M (1988) An overview of motor vehicle navigational/route guidance developments in Japan. The Japanese national paper for roads and traffic 2000. Berlin, September

Meehan C (1990) Cellular phones becoming indispensable. Ann Arobor News, February 28

Michalopoulos P Blake W \& Benke R (1990) Testing and field implementation of the Minnesota video detection system. Paper No. 890457 presented at the 69th Annual Meeting of the Transportation Research Board. Washington DC, January 7-11

Mobility 2000 (1989) Proceedings of a workshop on intelligent vehicle/highway systems. San Antonio Texas, February

Mobility $20(10(1990)$ Final report of the working group on advanced driver information systems (ADIS). March

Orne DE (1990) Organizing an intelligent vehicle/highway systems program - The Michigan department of transportation experience. Proceedings of the 22nd Interna- 
tional Symposium on Automotive Technology and Automation. Florence, Italy, May $14-18$

Panik F (1988) General PROMETHEUS strategy. Paper presented at the International Symposium on the EUREKA Program, Torino, Italy, April 22, 1988

Persaud BN Hall FL \& Hall LM (1990) Development and testing of the McMaster incident detection algorithm. Paper No. 890334 presented at the 69th Annual Meeting of the Trasportation Research Board. Washington DC, January 7-11

Rivard J (1987) Dynamic change - the global automotive suppliers" opportunity. The University of Michigan. Automotive Management Briefing Seminar, August

Rosen DA Mammano FJ \& Favort R (1970) An electronic route guidance system for highway vehicles. IEEE Transactions on Vehicular Technology VT-19

Stephens BW Rosen DA Mammano FJ \& Gibbs WL (1968) Third generation destination signing: An electronic route guidance system. Route Guidance Highway Research Record No. 265

Summer R \& Mammano F (1989) PATHFINDER system design. Record of the 1 st Vehicle Navigation and Information Systems Conference, September

US Congress Office of Technology Assessment (1989) Advanced vehicle/highway systems and urban traffic problems. Staff paper. September

US Department of Transportation Office of the Secretary (1989) Discussion paper on intelligent vehicle-highway systems, May

Underwood SE Chen K \& Ervin RD (1989) The future of intelligent vehicle-highway systems: A Delphi forecast of markets and sociotechnical determinants. The University of Michigan, November 